\title{
Celiac disease in toddler with atypical onset. Case report.
}

\section{Daniela Iacob1, Otilia Fufezan1, Dorin Farcău1, Gabriel Samaşcă², Adriana Slavcovici Dan Gheban ${ }^{4}$}

${ }^{1} 3^{\text {rd }}$ Pediatric Department, ${ }^{2} 2^{\text {nd }}$ Pediatric Department, ${ }^{3}$ Infectious Disease Department, ${ }^{4}$ Pathology Department, "Iuliu Haţieganu" University of Medicine and Pharmacy Cluj-Napoca, Romania

\begin{abstract}
Celiac disease is a chronic immune-mediated disorder induced in genetically susceptible individuals after ingestion of gluten proteins. An early diagnosis is of highest importance. Ultrasound might show small-bowel intussusception. We present a toddler with one month history of diarrhea and abdominal ultrasound showing ileo-ileal intussusception. Specific serological markers for celiac disease were positive. The duodenal endoscopy showed normal architecture but pathology indicated fully developed celiac disease (Marsh 3c). In conclusion, toddlers, who have even a short history of diarrhea with ultrasound showing ileo-ileal intussusception, can be suspected of celiac disease by positive serologic markers and can be confirmed by duodenal biopsy and pathology.
\end{abstract}

Keywords: celiac disease, ultrasound, duodenal biopsy, anti-endomysial and anti-transglutaminase antibodies, toddler.

\section{Introduction}

Celiac disease (CD) is a systemic chronic immunemediated disorder triggered after the ingestion of gluten proteins from wheat, rye, or barley in genetically susceptible individuals. About $10 \%$ of patients have a diagnostic delay of more than 10 years from symptom onset $[1,2]$. The three factors that cause $\mathrm{CD}$ are: an overresponsive immune system, the genetic predisposition, and factors such as gluten that turns on the autoimmune response. Primarily the small bowel mucosa concerning progressive inflammation and destruction of villus with induction of crypt hyperplasia is affected. The destruction starts in the duodenum and progresses toward the ileum. The damage decreases in severity toward the distal small intestine [3]. Due to the loss of villi, which absorb fluids, and hypertrophy of crypts, which produce

Received 08.06.2015 Accepted 25.06.2015

Med Ultrason

2016, Vol. 18, No 1, 116-119

Corresponding author: Daniela Iacob

3rd Pediatric Department

"Iuliu Haţieganu" University

of Medicine and Pharmacy

2-4 Campeni street,

400217 Cluj-Napoca, Romania

E-mail: iacobdaniela777@gmail.com fluids, chronic fluid excess results in the lumen of small bowel, this mechanism being able to induce intussusception [4]. Celiac disease can vary from subclinical to malabsorptive form. Due to this variable clinical picture an accurate diagnosis is difficult. Patients can present anemia and weight loss, chronic diarrhea/constipation, recurring abdominal distension and pain, intussusception, fatigue, and irritability $[5,6]$. Laboratory tests in $\mathrm{CD}$ show malabsorption. When $\mathrm{CD}$ is suspected the confirmation is done through endoscopy and duodenal biopsy in addition to antibody testing for anti-transglutaminase (TGA) and antiendomysial (EMA) antibodies IgA. These antibody testing are both sensitive and highly specific [7]. The duodenal biopsy proving the reduction or disappearance of the 'villi' together with crypts hyperplasia is the mandatory requirement for CD diagnosis, in accordance with the European Society for Pediatric Gastroenterology, Hepatology and Nutrition (ESPGHAN) [8]. The only effective treatment for CD is a strict lifelong gluten-free diet. In non-specific cases abdominal ultrasound and computed tomography are often required.

This report highlights the utility of abdominal ultrasound correlated with antibody testing and endoscopy with duodenal biopsy in the diagnosis of an atypical case of $\mathrm{CD}$ in a toddler. 


\section{Case report}

A 16 month old boy was admitted with one month history of diarrhea. The clinical onset was abrupt with 3 diarrheic stools daily. He received restrictive diet and oral antibiotics. After an initial one week improvement, he presented again diarrhea, with 12 watery stools daily. He was admitted to the Infectious Disease Department where Rotavirus was detected in his stools. After the resolution of the Rotavirus infection, due to the reoccurrence of diarrheic stools when diet was ceased, he was transferred to a pediatric hospital. Clinical examination showed an afebrile toddler, with normal weight and height, pale skin, diminished gluteal muscles, gracile legs, abdominal distension, timpanism at the abdomen percussion, discolored pasty stools (fig 1a). Laboratory investigations proved anemia, low serum iron, normal immunoglobulin A, negative stools for Rotavirus, bacteria or parasites. The patient underwent abdominal ultrasound using a Toshiba machine with a $5 \mathrm{MHz}$ probe, showing a 2 days persistent ileo-ileal intussusception, solved then spontaneously (fig $1 \mathrm{~b}, \mathrm{c}$ ).

Due to the clinical appearance of the patient and the ileo-ileal intussusception diagnosed by ultrasound, despite the short history of persistent diarrhea of only one month, serological tests for $\mathrm{CD}$ disease were performed. Both TGA and EMA antibodies IgA were positive. Endoscopy with duodenal biopsy was then performed. The endoscopy did not show any characteristic features. The pathology features according to Marsh classification indicated fully developed CD (Marsh 3c) showing marked villous blunting, increased surface intraepithelial lymphocytes and marked crypt hyperplasia (fig 1d).
Treatment consisted of a total gluten-free diet. One month after gluten withdrawal an obvious symptomatic improvement was observed. He will have regular ultrasound checks for abdominal pain, due to the increased risk for ileo-ileal intussusception.

\section{Discussions}

Studies from Europe and United States reported a prevalence of $C D$ in children aged between 2.5 and 15 years to be 3-13 per 1000 children [9]. The genes responsible for the development of $\mathrm{CD}$ are located on the HLA-class II complex and are called DQ2 and DQ8. It was reported that $90 \%$ to $95 \%$ of patients with CD inherit alleles encoding HLA-DQ2, and most of the remaining patients have HLA-DQ8 [10]. The clinical onset of $\mathrm{CD}$ varies widely, depending mostly on the patient's age, duration and extent of the disease, and presence of extra-intestinal manifestations. The clinical picture in CD may vary from major, to minor and silent form [11-13].

Transient intussusception can develop in children with $\mathrm{CD}$, being related to the uncoordinated peristalsis in the dilated small bowel loops. Most patients are usually asymptomatic, being identified by the typical target sign on abdominal ultrasound or CT. The small-bowel intussusception can be transient and self limiting if it is less than $3 \mathrm{~cm}$ long [6]. A common feature of intussusception in CD is its recurrent character [14-16]. The association between acute bowel intussusception and CD has been often described in children [17-19]. Instead, intussusception as the presenting symptom of pediatric $\mathrm{CD}$ has been rarely reported [20]. A small bowel intussusception was detected by ultrasound in our patient,

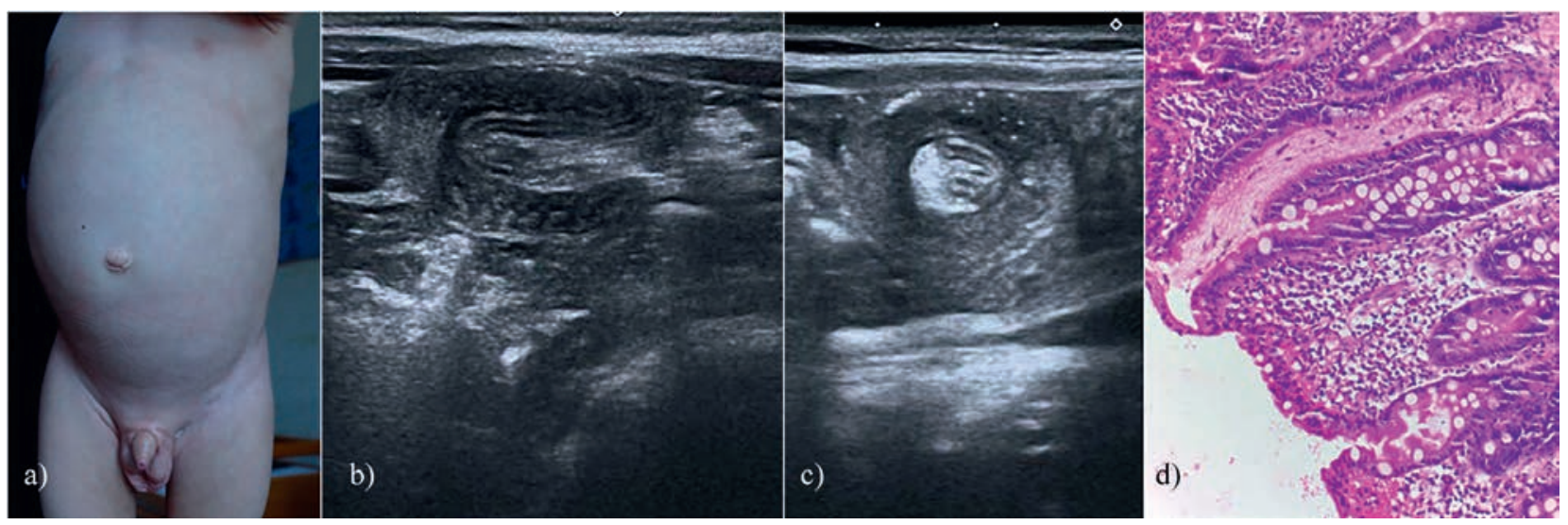

Fig 1. a) Clinical picture in CD: abdominal distension, muscle wasting; b) Abdominal ultrasound: small-bowel intussusception longitudinal view; c) Abdominal ultrasound: small-bowel intussusception - transverse view; d) Celiac disease, duodenal biopsy (H\&E): fully developed celiac disease (Marsh 3c) showing marked villous blunting, increased surface intraepithelial lymphocytes, and marked crypt hyperplasia. 
lasting for two days and being self limited. In difficult cases CT enterography is recommended which offers details of the bowel wall and mucosal pathology [21]. In suspected cases, $\mathrm{CD}$ endoscopy can prove the characteristic endoscopic features: cobble stone appearance of duodenal mucosa, notched appearance of duodenal folds, villous atrophy, and visible submucosal vessels. The sensitivity and specificity of the endoscopic findings were reported between $75 \%$ and $100 \%[22,23]$. Our patient did not show any endoscopic findings, probable due to the early diagnosis after gluten was introduced in his diet.

$\mathrm{CD}$ is proved by pathology, showing the degree of inflammatory infiltrate and villous atrophy through the Marsh grading system. Villous atrophy (Marsh type 3) represents the characteristic pathologic feature of $\mathrm{CD}$. The peculiarity of our patient consists of the short history of diarrhea, typical clinical aspect, normal endoscopic duodenal features and the pathology proving fully developed CD (Marsh 3c). The matching between the imagistic, endoscopic and pathological findings in old children and adults can be explained by the increasing severity of $\mathrm{CD}$ with age progression [24]. The serological tests used for detecting CD include specific and sensitive serological markers, such as EMA antibodies $(91-100 \%$ specificity and $88-100 \%$ sensitivity) and TGA antibodies (92-100\% sensitivity and $91-100 \%$ specificity) $[9,24,25]$. Our patient was proven with positive serology for TGA and EMA antibodies, that correlated with the pathological feature of Marsh $3 \mathrm{c}$ allowing the diagnosis of fully developed CD. In CD treatment a lifelong total exclusion of gluten is imposed [26].

In conclusion, in toddlers having even a short history of diarrhea, with a clinical appearance suggestive for malabsorption, with ultrasound findings showing ileoileal intussusception, the diagnosis of $\mathrm{CD}$ can be suspected by positive serologic EMA or TGA antibodies and confirmed pathologically via endoscopy and duodenal biopsy, proving a fully developed CD (Marsh 3c).

Acknowledgement: This paper was published under the frame of the European Social Found, Human Resources Development Operational Programme 2007-2013, project no. POSDRU/159/1.5/S/138776

\section{References}

1. Green PH, Cellier C. Celiac disease. N Engl J Med 2007; 357: 1731-1743.

2. West J, Logan RF, Hill PG, et al. Seroprevalence, correlates, and characteristics of undetected celiac disease in England. Gut 2003; 52: 960-965.
3. Ciclitira PJ, Moodie SJ. Transition of care between paediatric and adult gastroenterology: coeliac disease. Best Pract Res Clin Gastroenterol 2003; 17: 181-195.

4. Catassi C, Kryszak D, Louis-Jacques O, et al. Detection of celiac disease in primary care: a multicenter case-finding study in North America. Am J Gastroenterol 2007; 102: 1454-1460.

5. Green PH, Jabri B. Coeliac disease. Lancet 2003; 362: 383391.

6. Eid M, Abougabal A, Zeid A. Celiac disease: Do not miss that diagnosis! Egypt J Radiol Nucl Med 2013; 44: 727735 .

7. Van der Windt DA, Jellema P, Mulder CJ, Kneepkens CM, van der Horst HE. Diagnostic testing for celiac disease among patients with abdominal symptoms: a systematic review. JAMA 2010; 303: 1738-1746.

8. Cataldo F, Pitarresi N, Accomando S, et al. Epidemiological and clinical features in immigrant children with celiac disease: an Italian multicentre study. Dig Liver Dis 2004; 36: $722-729$

9. Hill ID, Dirks MH, Liptak GS, et al. Guideline for the diagnosis and treatment of celiac disease in children: recommendations of the North American Society for Pediatric Gastroenterology, Hepatology and Nutrition. J Pediatr Gastroenterol Nutr. 2005; 40: 1-19.

10. Lionetti E, Catassi C. Co-localization of gluten consumption and HLA-DQ2 and -DQ8 genotypes, a clue to the history of celiac disease. Dig Liver Dis 2014; 46: 10571063.

11. Di Sabatino A, Corazza GR. Coeliac disease. Lancet 2009; 373: 1480-1493.

12. Rampertab SD, Pooran N, Brar P, Singh P, Green PH. Trends in the presentation of celiac disease. Am J Med 2006; 119: 355.e9-14.

13. Tack GJ, Verbeek WH, Schreurs MW, Mulder CJ. The spectrum of celiac disease: epidemiology, clinical aspects and treatment. Nat Rev Gastroenterol Hepatol 2010; 7: 204213.

14. Grados A, Bernard F, Coquet-Reinier B, et al. Invagination intestinale aigue revelant une maladie coeliaque: a propos d'un cas et revue de la litterature. Rev Med Interne 2011; 32: 628-632.

15. Martinez G, Israel NR, White JJ. Celiac disease presenting as entero-enteral intussusception. Pediatr Surg Int 2001; 17: 68-70.

16. Teitelbaum JE. Clinical quiz. Small bowel-small bowel intussusception. J Pediatr Gastroenterol Nutr 2004; 38: 435441.

17. Dodds BF, Aguancha SI, Santamarina RM, Vega SJ. Celiac disease presenting as an intestinal intussusception. Report of one case. Rev Med Chil 2008; 136: 1179-1182.

18. Navarro O, Daneman A. Intussusception. Part 3: Diagnosis and management of those with an identifiable or predisposing cause and those that reduce spontaneously. Pediatr Radiol 2004; 34: 305-312.

19. Gheibi S. Association between Celiac Disease and Intussusceptions in Children: Two Case Reports and Literature 
Review. Pediatr Gastroenterol Hepatol Nutr 2013; 16: 269272.

20. Reilly NR, Aguilar KM, Green PH. Should intussusception in children prompt screening for celiac disease? J Pediatr Gastroenterol Nutr 2013; 56: 56-59.

21. Soyer P, Boudiaf M, Dray X, et al. CT enteroclysis features of uncomplicated celiac disease: retrospective analysis of 44 patients. Radiology 2009; 253: 416-424.

22. Ravelli AM, Tobanelli P, Minelli L, Villanacci V, Cestari R. Endoscopic features of celiac disease in children. Gastrointest Endosc 2001; 54: 736-742.
23. Brocchi E, Tomassetti P, Misitano B, et al. Endoscopic markers in adult coeliac disease. Dig Liver Dis 2002; 34: 177-182.

24. Lebwohl B, Rubio-Tapia A, Assiri A, Newland C, Guandalini S. Diagnosis of celiac disease. Gastrointest Endosc Clin N Am 2012; 22: 661-677.

25. Green PH, Jabri B. Celiac disease. Annu Rev Med 2006; 57: 207-221.

26. Rashtak S, Murray JA. Review article: coeliac disease, new approaches to therapy. Aliment Pharmacol Ther 2012; 35: 768-781. 